\title{
Impacto da conversão floresta - pastagem nos estoques e na dinâmica do carbono e substâncias húmicas do solo no bioma Amazônico
}

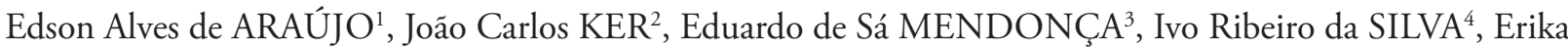 \\ Karla OLIVEIRA ${ }^{5}$
}

\begin{abstract}
RESUMO
O presente estudo avaliou as consequências do desmatamento e a utilizaçáo do solo com Brachiaria brizantha em relaçáo ao estoque e dinâmica de $\mathrm{C}$ e fraçóes húmicas em duas floresta-pastagem no Acre. A primeira localizada sequências município de Rio Branco em área de Floresta Aberta com bambu e palmeira e duas pastagens de B. brizantha de 3 e 10 anos com predomínio de Argissolo Vermelho-Amarelo alítico plíntico. O segundo situado no município de Senador Guiomard em área de Floresta Densa e pastagem de B. brizantha de 20 anos em Latossolo Vermelho-Amarelo distrófico. Em cada local foram coletadas, em triplicata, amostras de solos nas profundidades de 0-5, 5-10, 10-20 e 20-40 cm. Nestas amostras foram avaliadas as características físico-químicas, o C das substâncias húmicas e da matéria orgânica leve, e a composição isotópica do solo e das respectivas fraçóes orgânicas até $1 \mathrm{~m}$ de profundidade, determinando o percentual de $\mathrm{C}$ derivado da pastagem e da floresta. Houve incremento nos estoques de $\mathrm{C}$ do solo e nos valores de $\delta^{13} \mathrm{C}$ do solo com o tempo de utilizaçáo da pastagem, em ambas as sucessóes. A porcentagem de $\mathrm{C}$ derivado de pastagem foi expressiva na camada superficial do sistema com 20 anos de uso, com proporçôes que chegaram a $70 \%$ do $\mathrm{C}$ total. Os valores de $\delta^{13} \mathrm{C}$ para os ácidos húmicos variaram de $-12,19$ a $-17,57 \%$, indicando maior proporção de $\mathrm{C}$ derivado da pastagem. A estabilidade estrutural da MOS, inferida pela relação humina com as fraçóes ácido fúlvico e ácido húmico (HUM/FAF+FAH), tenderam a diminuir nos ecossistemas de pastagem quando comparada com as florestas naturais.
\end{abstract}

PALAVRAS-CHAVE: Amazônia Ocidental, mudanças de uso da terra, Brachiaria brizantha cv Marandu , abundância natural do ${ }^{13} \mathrm{C}$.

\section{Impact of forest-pasture conversion on stocks and dynamics of soil carbon and humic substances in the Amazon}

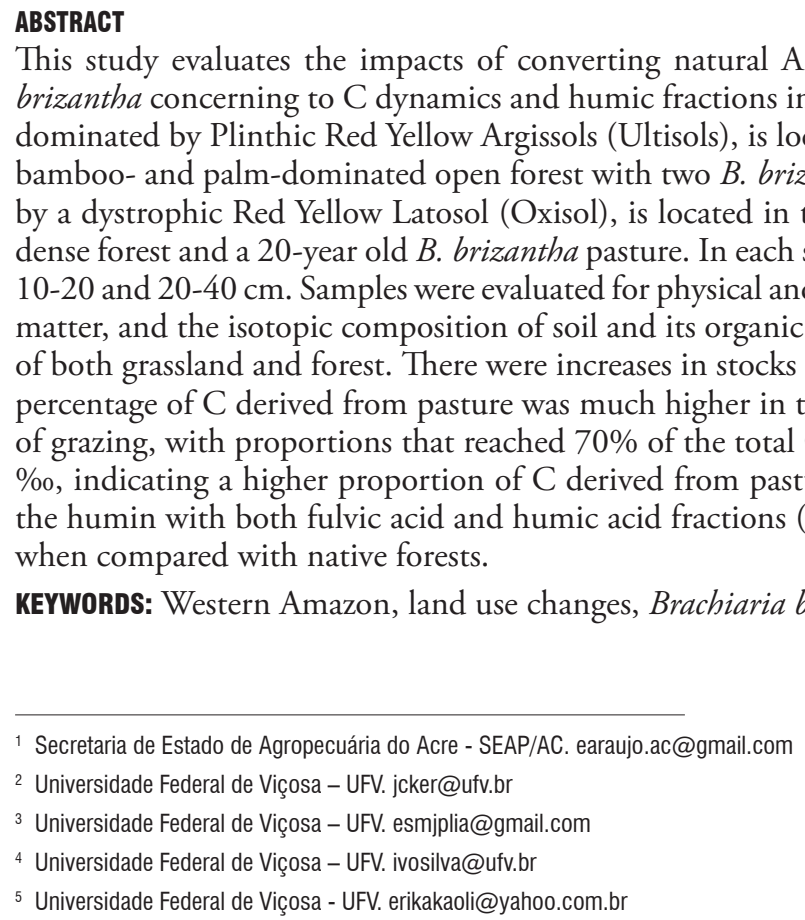
when compared with native forests.

\footnotetext{
1 Secretaria de Estado de Agropecuária do Acre - SEAP/AC. earaujo.ac@gmail.com

2 Universidade Federal de Viçosa - UFV. jcker@ufv.br

3 Universidade Federal de Viçosa - UFV. esmjplia@gmail.com

${ }^{4}$ Universidade Federal de Viçosa - UFV. ivosilva@ufv.br

5 Universidade Federal de Viçosa - UFV. erikakaoli@yahoo.com.br
}

This study evaluates the impacts of converting natural Amazonian forests in Brazil to pasture dominated by Brachiaria brizantha concerning to $\mathrm{C}$ dynamics and humic fractions in two soil chronosequences in the Acre State, Brazil. The first site, dominated by Plinthic Red Yellow Argissols (Ultisols), is located in the municipality of Rio Branco and comprises an area of bamboo- and palm-dominated open forest with two B. brizantha pastures of 3 and 10 years old. The second site, dominated by a dystrophic Red Yellow Latosol (Oxisol), is located in the municipality of Senador Guiomard and comprises an area of dense forest and a 20-year old B. brizantha pasture. In each site soil samples were collected in triplicate at depths of 0-5, 5-10, 10-20 and 20-40 cm. Samples were evaluated for physical and chemical characteristics, $C$ of humic substances and light organic matter, and the isotopic composition of soil and its organic fractions to $1 \mathrm{~m} \mathrm{depth}$, determining the percentage of $\mathrm{C}$ derived of both grassland and forest. There were increases in stocks of soil $\mathrm{C}$ and $\delta^{13} \mathrm{C}$ soil with the time of grazing in both sites. The percentage of $\mathrm{C}$ derived from pasture was much higher in the surface layer of the Senador Guiomard site following 20 years of grazing, with proportions that reached $70 \%$ of the total C. $\delta^{13} \mathrm{C}$ values for the humic acids ranged from -12.19 to -17.57 $\%$, indicating a higher proportion of $\mathrm{C}$ derived from pasture. The MOS structural stability inferred by the relationship of the humin with both fulvic acid and humic acid fractions (HUM / FAF + FAH) tended to decrease in grassland ecosystems

KEYWORDS: Western Amazon, land use changes, Brachiaria brizantha cv Marandu, natural abundance of $13 \mathrm{C}$. 


\section{INTRODUÇÃO}

A Amazônia Legal, cuja área é de 5,2 milhóes de $\mathrm{km}^{2}$, possuía até 2007 uma área cumulativa desmatada correspondente a $691.123 \mathrm{~km}^{2}$, o equivalente a cerca de $17,2 \%$ de toda a floresta Amazônica brasileira. Cerca de $80 \%$ da área desmatada tem sido utilizada com pastagens plantadas e estima-se que metade desta área esteja degradada e, em alguns casos, abandonadas (Dias-Filho e Andrade, 2006).

O Estado do Acre, localizado na porção ocidental da Amazônia, possui área territorial de aproximadamente $164.220 \mathrm{~km}^{2}$, o equivalente a 4\% da área da Amazônica brasileira e a $1,9 \%$ do território nacional e apresenta cerca de $11,7 \%\left(19.200 \mathrm{~km}^{2}\right)$ de sua área total desflorestada (INPE, 2008). O desmatamento tem se concentrado principalmente nos municípios da regiấo Leste do Estado. Do total desmatado, até 2004 , em torno de $81 \%\left(13.352 \mathrm{~km}^{2}\right)$ eram utilizados com pastagens (Oliveira et al., 2006). A gramínea forrageira mais utilizada tem sido a Brachiaria brizantha cv Marandu (Dias-Filho e Andrade, 2006).

A conversão de áreas de floresta amazônica em pastagem resulta em mudanças na quantidade e qualidade da biomassa aérea (Fearnside e Barbosa, 1998), nas características físicas e químicas do solo (Pereira et al., 2000; Longo e Espíndola, 2000; Makewitz et al., 2004) e na emissão de gases de efeito estufa durante as operaçóes de queima da floresta e, ou das pastagens (Fearnside, 2002). Com a introdução da pastagem os estoques de $\mathrm{C}$ no solo podem decrescer nos primeiros anos da implantação, e aumentar nos anos seguintes, até atingir valores próximos ou superiores aos existentes antes da conversão (Feigl et al., 1995; Melo, 2003; Salimon et al., 2007). Em menor proporçáo, alguns trabalhos têm constatado decréscimo no conteúdo de matéria orgânica do solo com o tempo de conversáo floresta-agricultura (Desjardins et al., 1994; García-Oliva et al., 1994; Veldkamp, 1994). Este fato se deve a rápida mineralização do $\mathrm{C}$ biodegradável proveniente da floresta e de fatores que influenciam a taxa de mineralização do carbono orgânico e conseqüentemente relacionados à atividade biológica do solo, como propriedades do ecossistema (temperatura, presença ou ausência de bases trocáveis e drenagem), mecanismos físicos de proteção de agregados do solo, recalcitrância bioquímica e duração da exposição (Volkoff e Cerri, 1981; Bernoux et al., 1999; Koutika et al., 1999, 2000). A diferenciação das fontes de $\mathrm{C}$ derivada da floresta e da pastagem pode ser efetuada com o emprego de técnicas isotópicas baseadas na abundância natural do ${ }^{13} \mathrm{C}$ (Bernoux et al., 1998a). Grande parte das espécies de plantas em florestas tropicais possui ciclo fotossintético do tipo C3. As gramíneas possuem ciclo fotossintético do tipo C4. As plantas do tipo C4 discriminam menos e são mais enriquecidas em ${ }^{13} \mathrm{C}$, sendo que os valores de $\delta^{13} \mathrm{C}$ situam-se entre - $6 \%$ e - $19 \%$ mais empobrecidas em ${ }^{13} \mathrm{C}$ cujos valores oscilam entre - 20 \%o e - 34 \%o (em média - $27 \%$ ) (Smith e Epstein, 1971). Esta diferença tem sido utilizada para estudar as modificaçóes na relação isotópica do $\mathrm{C}$ do solo decorrente da alteração da cobertura florestal amazônica (Moraes et al., 1996; Bernoux et al., 1999; Desjardins et al., 2004).

A substituição de sistemas florestais naturais por ecossistemas de pastagens na Amazônia altera também a distribuição das frações humificadas do solo (Fernandes et al., 1999). Apesar disso, na Amazônia, poucos são os trabalhos que evidenciam as alteraçóes da composição isotópica do $\mathrm{C}$ nas substâncias húmicas do solo decorrentes de mudanças de uso da terra. Investigaçóes dessa natureza têm sido realizadas em solos de origem vulcânica (Hiradate et al., 2004), em solos do continente africano (Piccolo et al., 2005; Spaccini et al., 2006), em sedimentos de rio (Bernardes et al., 2004) e como auxiliar na datação da matéria orgânica do solo e da fração humina (Gouveia e Pessenda, 1999).

O objetivo deste trabalho foi avaliar o impacto da conversão da floresta amazônica em pastagem no conteúdo e na dinâmica das fraçóes da matéria orgânica do solo para distintos pedoambientes da região Leste do Acre.

\section{MATERIAL E MÉTODOS}

\section{LOCAIS DE ESTUDO}

A área de estudo localiza-se na região leste do Acre, nos municípios de Rio Branco e Senador Guiomard. No município de Rio Branco, o trabalho foi realizado na Fazenda Batista na altura do $\mathrm{km} 50$ da rodovia Transacreana (Coordenadas UTM: 19L, N 583653 E 8896150). No local predominam Argissolos Vermelho-Amarelos plínticos em associação com Plintossolos. Em geral, apresentam solum raso a pouco profundo, imperfeitamente drenados a mal drenados e, por vezes, com argila de atividade alta e fertilidade natural variável (eutróficos, epieutróficos e distróficos) (Brasil, 1976; Acre, 2006). A vegetação dominante é do tipo Floresta Tropical Aberta, com ocorrência freqüente de bambus (Acre, 2006). O relevo varia de suave ondulado a ondulado. A média anual da precipitação pluviométrica varia de 1.877 a $1.982 \mathrm{~mm}$ e a temperatura média anual é de $25^{\circ} \mathrm{C}$ (Acre, 2006).

A sucessão estudada inclui a floresta original (FA) e duas pastagens de $B$. brizantha, implantadas há 3 e 10 anos (P3A e P10A, respectivamente). A primeira foi implantada em 2001 após derrubada e queima da floresta; não foi utilizado corretivo ou adubo. A segunda em 1994; não foi utilizado corretivo ou adubo; a área foi queimada após o desmate (1994) e novamente em 1999 (cinco anos depois). O braquiarão (B. brizantha) foi semeado simultaneamente com a puerária (Pueraria phaseoloides). Observou-se a ocorrência de plantas

(em média - $13 \%$ ); as de tipo C3 discriminam mais e são 
invasoras como o assa-peixe (Vernonia spp.), jurubeba (Solanum crinitum), malva (Urena lobata), e tiririca (Cyperus spp.).

No município de Senador Guiomard, o estudo foi conduzido na Fazenda Ouro Verde, distante $10 \mathrm{~km}$ da sede do município (Coordenadas UTM: 19L, N 8871114, E 641824). No local, predominam Latossolos VermelhoAmarelo, em geral, cauliníticos, distróficos, profundos, bem drenados em ambientes de relevo plano a suave ondulado (Brasil, 1976; Acre, 2006). A floresta nativa predominante é a do tipo Floresta Tropical Densa (Acre, 2006). A precipitação pluviométrica e a temperatura média anual são similares as da região de Rio Branco. As áreas estudadas incluem a floresta original (FB) e uma pastagem de B. brizantha de 20 anos (P20B), implantada em 1984; em que não foi realizada queima nos últimos 10 anos; não foi gradeada e não se utilizou corretivo, nem fertilizante. A mesma apresenta pouca infestação por plantas invasoras.

\section{AMOSTRAGEM DO SOLO E MÉTODOS ANALÍTICOS}

Em cada ambiente (FA, P3A, P10A, FB e P20B) foram abertas três minitrincheiras de $1 \mathrm{~m}$ de profundidade, distanciadas aproximadamente $500 \mathrm{~m}$ uma da outra e retiradas amostras de aproximadamente $1 \mathrm{~kg}$ de solo nas profundidades de 0-5; 5-10; 10-20 e 20-40 cm da superfície. As amostras foram secas ao ar e peneiradas. A fração inferior a $2 \mathrm{~mm}$ foi submetida as seguintes análises físicas e químicas (Embrapa, 1997): pH em água (relação solo: solução 1:2,5); teores de cálcio, magnésio e alumínio trocáveis, extraídos com solução de $\mathrm{KCl} 1 \mathrm{~mol} \mathrm{~L}^{-1}$, sendo quantificados por espectrofotometria de absorção atômica, e o $\mathrm{Al}^{3+}$ por titulação com solução $\mathrm{NaOH}$ $0,025 \mathrm{~mol} \mathrm{~L}^{-1}$; potássio trocável extraído com solução de $\mathrm{HCl} 0,05 \mathrm{~mol} \mathrm{~L}^{-1}$ e quantificado por fotometria de chama; fósforo disponível, extraído com solução de $\mathrm{HCl} \mathrm{0,05 \textrm {mol }}$ $\mathrm{L}^{-1}+\mathrm{H}_{2} \mathrm{SO}_{4} 0,0125 \mathrm{~mol} \mathrm{~L}^{-1}$ (Mehlich-1) e determinado por colorimetria. A densidade do solo foi determinada por meio do método do anel de Kopeck (Embrapa, 1997) com três repetiçôes para cada profundidade. Para a camada de 20-40 $\mathrm{cm}$ a densidade foi estimada por meio de equaçóes lineares múltiplas que relacionam teor de argila, $\mathrm{C}$ e pH (Bernoux et al., 1998b; Melo, 2003).

A extração e fracionamento químico das frações ácidos húmicos (FAH), ácidos fúlvicos (FAF) e humina (HUM) foi realizada conforme metodologia preconizada pela Sociedade Internacional de Substâncias Húmicas - IHSS (Swift, 1996). Neste caso pesou-se $1 \mathrm{~g}$ de TFSA passado previamente em almofariz, e colocado em tubos de centrífuga juntamente com $10 \mathrm{~mL}$ de $\mathrm{NaOH} 0,1 \mathrm{~mol} \mathrm{~L}^{-1}$. Em seguida, agitou-se por 1 hora a $12 \mathrm{rpm}$ em agitador horizontal e colocado em repouso por 12 horas. Decorrido esse tempo, centrifugou-se a $3000 \mathrm{~g}$ por 20 minutos. Transferiu-se o sobrenadante para béquer de $50 \mathrm{~mL}$. Esse procedimento foi repetido por mais três vezes, excetuando a centrifugaçáo e o tempo de descanso de um dia para o outro, deixando-se em descanso por 1 hora. O precipitado obtido, que inclui a fração HUM, foi transferido para tubos de digestão e seco em estufa a $45^{\circ} \mathrm{C}$. $\mathrm{O}$ conteúdo do sobrenadante teve seu $\mathrm{pH}$ ajustado para um valor inferior a 2,0 (entre 1,5 a 1,8) com $\mathrm{H}_{2} \mathrm{SO}_{4}$ concentrado, com o propósito de precipitar a fração $\mathrm{AH}$. Deixou-se a suspensão em repouso por 18 horas, separando-se, então, a FAH da fração solúvel (FAF) por centrifugação $(3000 \mathrm{rpm}$ por 10 minutos). A fração $\mathrm{AF}$ foi transferida para baláo volumétrico de $50 \mathrm{~mL}$, completando-se seu volume com água destilada. Ao precipitado (FAH), adicionaram-se $30 \mathrm{~mL}$ de $\mathrm{NaOH} 0,1 \mathrm{~mol} \mathrm{~L}^{-1}$, agitando e deixando em repouso por 1 hora. Depois, o precipitado redissolvido foi transferido para balão volumétrico de $50 \mathrm{~mL}$, completando-se o volume com água destilada. $\mathrm{Na}$ determinação do $\mathrm{C}$ orgânico contido no solo e nas fraçóes húmicas (FAF, FAH e HUM), utilizou-se o método da dicromatometria, com aquecimento externo, conforme Yeomans e Bremner (1988). Para a determinação do nitrogênio das fraçôes húmicas (HUM, FAF e AH) utilizou-se os produtos do fracionamento acima, conforme adaptaçóes de Bremner e Mulvaney (1982) e Tedesco et al. (1995). A fração leve da matéria orgânica (MOL) foi extraída por densimetria em água (Anderson e Ingram, 1993). A quantificação de C foi realizada por combustão a seco em analisador elementar (CHNS, Perkin Elmer, Optima 2400) em razáo de não ter se obtido material orgânico suficiente (principalmente a maiores profundidades) para ser utilizada na análise.

Os estoques de $\mathrm{C}$ para cada profundidade foram obtidos multiplicando-se o teor de $\mathrm{C}\left(\mathrm{g} \mathrm{kg}^{-1}\right)$, pela densidade do solo $\left(\mathrm{kg} \mathrm{m}^{-3}\right)$ e pela espessura $\mathrm{h}(\mathrm{m})$ e os resultados expressos em $\mathrm{Mg} \mathrm{ha}^{-1}$.

Para análise isotópica sub-amostras de solo até $1 \mathrm{~m}$ de profundidade (0-5, 5-10, 10-20, 20-40, 40-60 e 60-10 cm) e das fraçóes da MOS foram maceradas em almofariz de ágata até granulometria de pó. A razão isotópica ${ }^{13} \mathrm{C} /{ }^{12} \mathrm{C}$ das amostras foi determinada em espectrômetro de massa de razão isotópica (ANCA-GSL, Sercon, UK), no Laboratório de Isótopos Estáveis do Departamento de Solos da Universidade Federal de Viçosa (UFV).

A abundância natural de $\mathrm{C}$ foi expressa em $\delta^{13} \mathrm{C}$ em partes por mil (\%o), usando como referência o padrão internacional PDB (Pee Dee Belemnita), de acordo com a seguinte equação:

$$
\delta{ }^{13} C=\left(\frac{R_{\text {amostra }}-R_{\text {padrão }}}{R_{\text {padrão }}}\right) \times 1000
$$

Em que: $\mathrm{R}_{\text {amostra }}$ é a razão isotópica ${ }^{13} \mathrm{C} /{ }^{12} \mathrm{C}$ da amostra e $\mathrm{R}_{\text {padráo }}$ é a razáo isotópica ${ }^{13} \mathrm{C} /{ }^{12} \mathrm{C}$ do padráo certificado internacional. 
A participação do C remanescente da floresta (Cf) e o introduzido pela pastagem $(\mathrm{Cp})$ na MOS e nas substâncias húmicas, foram calculados conforme as equaçôes abaixo:

$$
\begin{gathered}
C p(\%)=\frac{\delta-\delta_{0}}{\delta c-\delta_{0}} \times 100 \\
C f(\%)=100-C p
\end{gathered}
$$

Em que: $\delta=\delta^{13} \mathrm{C}$ da amostra de solo sob pastagem; $\delta \mathrm{c}=$ valor de $\delta^{13} \mathrm{C}$ da planta C 4 B. brizantha $(-13 \%)$; $\delta \mathrm{o}=$ valor de $\delta^{13} \mathrm{C}$ do solo sob floresta.

\section{RESULTADOS E DISCUSSÃO}

\section{CARACTERÍSITICAS FÍSICAS E QUÍMICAS DOS AMBIENTES ESTUDADOS}

Os solos dos ambientes de floresta (FA e FB) diferiram entre si principalmente quanto ao teor de $\mathrm{C}$ orgânico, quanto à textura e em termos de fertilidade (Tabela 1). Tanto o ambiente de floresta (FA) como as pastagens (P3A e P10A), pertencentes à primeira sucessão, apresentam maiores proporçôes da fração silte. Esta característica é marcante em alguns solos do Acre que tiveram os processos de pedogênese diminuídos em virtude da natureza pelítica do material de origem sedimentar (argilitos e siltitos) (Brasil, 1976) e de evidências atuais de clima árido no passado, tais como a ocorrência de veios de gipsita (gesso) e material carbonático da Formação Solimôes (Kronberg e Benchimol, 1992; Latrubesse e Iriondo, 1994).

Os teores de $\mathrm{P}$ disponível e $\mathrm{C}$ orgânico foram baixos e concentram-se principalmente nos primeiros centímetros da superfície $(0-5 \mathrm{~cm})$. Isso sugere que os maiores valores de somas de bases (SB) e P disponível são devidos ao processo de ciclagem de nutrientes favorecidos pela serapilheira e raízes. Esse fato é corroborado pela correlação positiva e significativa encontrada entre o C e SB $(r=0,76, p<0,05, n=20)$ e C e $\mathrm{P}(\mathrm{r}=0,80, \mathrm{p}<0,05, \mathrm{n}=20)$. Isso sugere que a MOS é a principal variável que controla os teores de $\mathrm{P}$ e bases trocáveis nesses ecossistemas.

Destaca-se o teor mais elevado de P no ambiente P10A $\left(13 \mathrm{mg} \mathrm{dm}^{-3}\right)$. Como essa pastagem encontra-se em ambiente de solos que ficam encharcados boa parte do ano, além do processo de compactação, isso cria uma zona de redução (com cores acinzentadas) em superfície, podendo favorecer o acúmulo de matéria orgânica e a liberação de P ligado ao ferro (Ponnamperuma, 1972; Lima et al., 2005).

Os solos sob floresta primária apresentaram maior acidez ativa do que nas áreas de pastagens, provavelmente pelo efeito da adição de cinzas ao solo no processo de conversão (derruba e queima) da floresta em pastagem. No processo de

\begin{tabular}{|c|c|c|c|c|c|c|c|c|c|c|}
\hline Prof. & Areia & Silte & Argila & $\mathrm{pH}$ & SB & $\mathrm{Al}^{3+}$ & C & $\mathrm{V}$ & $P$ & Ds \\
\hline ------- cm -------- & ------- & $-\mathrm{g} \mathrm{kg}^{-}$ & -------- & $\mathrm{H}_{2} \mathrm{O}$ & ------ & $k g^{-1}$ & $\mathrm{~g} \mathrm{~kg}^{-1}$ & $\%$ & $\mathrm{mg} \mathrm{dm} \mathrm{m}^{-3}$ & $\mathrm{~kg} \mathrm{dm}^{-3}$ \\
\hline
\end{tabular}

Tabela 1 - Principais características físicas e químicas dos solos dos ecossistemas

\begin{tabular}{|c|c|c|c|c|c|c|c|c|c|c|}
\hline $0-5$ & 270 & 510 & 210 & 5,4 & 5,1 & 0,5 & 17,00 & 52 & 5 & 1,09 \\
\hline $5-10$ & 250 & 550 & 200 & 5,4 & 2,7 & 0,4 & 9,93 & 40 & 2 & 1,22 \\
\hline $10-20$ & 260 & 530 & 210 & 5,3 & 2,2 & 0,4 & 7,97 & 32 & 2 & 1,35 \\
\hline $20-40$ & 230 & 500 & 280 & 5,0 & 2,9 & 1,4 & 7,18 & 29 & 6 & 1,20 \\
\hline Valor médio & 253 & 523 & 225 & 5,3 & 3,2 & 0,7 & 10,52 & 38 & 4 & 1,22 \\
\hline \multicolumn{11}{|c|}{ Pastagem de 3 anos (P3A) } \\
\hline $0-5$ & 140 & 610 & 250 & 6,0 & 8,2 & 0,3 & 15,34 & 68 & 4 & 1,17 \\
\hline $5-10$ & 130 & 640 & 230 & 5,7 & 5,4 & 0,4 & 9,04 & 54 & 2 & 1,37 \\
\hline $10-20$ & 150 & 570 & 280 & 5,4 & 4,3 & 0,9 & 6,71 & 46 & 1 & 1,38 \\
\hline $20-40$ & 150 & 540 & 310 & 5,1 & 3,1 & 1,9 & 4,96 & 29 & 1 & 1,25 \\
\hline Valor médio & 143 & 590 & 268 & 5,6 & 5,3 & 0,9 & 9,01 & 49 & 2 & 1,29 \\
\hline \multicolumn{11}{|c|}{ Pastagem de 10 anos (P10A) } \\
\hline $0-5$ & 310 & 500 & 200 & 7,1 & 11,8 & 0,2 & 32,05 & 89 & 13 & 1,31 \\
\hline $5-10$ & 320 & 510 & 180 & 7,2 & 8,9 & 0,1 & 16,52 & 86 & 6 & 1,42 \\
\hline $10-20$ & 300 & 490 & 210 & 6,6 & 8,3 & 0,5 & 6,76 & 75 & 3 & 1,44 \\
\hline $20-40$ & 180 & 350 & 470 & 6,0 & 13,6 & 3,3 & 6,64 & 66 & 2 & 1,18 \\
\hline Valor médio & 278 & 463 & 265 & 6,7 & 10,7 & 1,0 & 15,49 & 79 & 6 & 1,34 \\
\hline
\end{tabular}

Sequência 1 - município de Rio Branco; Floresta (FA) - Argissolo Vermelho-Amarelo alítico plíntico 


\begin{tabular}{|c|c|c|c|c|c|c|c|c|c|c|}
\hline Prof. & Areia & Silte & Argila & $\mathrm{pH}$ & SB & $\mathrm{Al}^{3+}$ & C & V & $P$ & Ds \\
\hline ------ cm - & -.-- & $\mathrm{g} \mathrm{kg}^{-}$ & ------ & $\mathrm{H}_{2} \mathrm{O}$ & ------ & $\mathrm{kg}^{-1}$----- & $\mathrm{g} \mathrm{kg}^{-1}$ & $\%$ & $\mathrm{mg} \mathrm{dm}^{-3}$ & $\mathrm{~kg} \mathrm{dm}^{-3}$ \\
\hline
\end{tabular}

Sequência 2 - município de Senador Guiomard ;Floresta (FB) - Latossolo Vermelho-Amarelo distrófico

\begin{tabular}{|c|c|c|c|c|c|c|c|c|c|c|}
\hline $0-5$ & 590 & 170 & 240 & 4,6 & 1,4 & 0,6 & 30,98 & 18 & 2 & 1,21 \\
\hline $5-10$ & 520 & 170 & 310 & 4,2 & 0,8 & 1,3 & 17,77 & 10 & 2 & 1,17 \\
\hline $10-20$ & 440 & 170 & 390 & 4,2 & 0,5 & 1,6 & 12,98 & 6 & 1 & 1,33 \\
\hline $20-40$ & 430 & 180 & 390 & 4,3 & 0,3 & 1,8 & 9,51 & 4 & 1 & 1,18 \\
\hline Valor médio & 495 & 173 & 333 & 4,3 & 0,8 & 1,3 & 17,81 & 10 & 2 & 1,22 \\
\hline \multicolumn{11}{|c|}{ Pastagem de 20 anos (P20B) } \\
\hline $0-5$ & 560 & 150 & 290 & 4,6 & 1,5 & 0,9 & 33,19 & 16 & 3 & 1,4 \\
\hline $5-10$ & 500 & 150 & 350 & 4,4 & 0,8 & 1,2 & 14,23 & 9 & 1 & 1,43 \\
\hline $10-20$ & 450 & 150 & 400 & 4,4 & 0,5 & 1,4 & 11,57 & 5 & 1 & 1,3 \\
\hline $20-40$ & 420 & 130 & 440 & 4,4 & 0,1 & 1,2 & 9,52 & 1 & 0 & 1,22 \\
\hline Valor médio & 483 & 145 & 370 & 4,5 & 0,7 & 1,2 & 17,13 & 8 & 1 & 1,34 \\
\hline
\end{tabular}

Notação: $\mathrm{SB}=$ soma de bases; $\mathrm{Al}^{3+}=$ alumínio trocável; $\mathrm{C}=$ carbono orgânico; $\mathrm{V}=$ saturação de bases $(\mathrm{SB}+\mathrm{H}+\mathrm{Al}) ; \mathrm{P}$ = fósforo; $\mathrm{Ds}=$ densidade do solo.

queima antropogênica da floresta são disponibilizados para o solo e atmosfera quantidades consideráveis de $\mathrm{C}$ e nutrientes provenientes da queima da biomassa acima e abaixo do solo (Kauffman et al., 1995; Markewitz et al., 2004). Durante o processo de encharcamento do solo, nos ecossistemas da sucessão FA-P3A-P10A, possivelmente, ocorrem mudanças substancias, tais como: a depleção de $\mathrm{O}_{2}, \mathrm{NO}_{3}^{-}$; formação de $\mathrm{Fe}^{2+}, \mathrm{Mn}^{2+}$ e $\mathrm{H}_{2} \mathrm{~S}$, dentre outros, os quais requerem $\mathrm{H}^{+}$ durante estes processos, fazendo com que ocorra incremento nos valores de $\mathrm{pH}$ (Ponnamperuma, 1972; Stevenson e Cole, 1999; Lima et al., 2005).

As maiores proporçóes de C orgânico para o ambiente de mata FB sugerem estar associado ao tipo de cobertura florestal (floresta densa), a posiçáo na paisagem (em locais de relevo plano e, portanto de maior estabilidade), maior interação da MOS com minerais de argila, com a distrofia $(\mathrm{V}<50 \%)$ e baixo conteúdo de $\mathrm{P}$ disponível do meio e toxidex por alumínio, fatores que favorecem o acúmulo de matéria orgânica no solo. $\mathrm{O}$ incremento de $\mathrm{C}$ em superfície nos ecossistemas de pastagem são decorrentes da decomposição de resíduos da parte aérea e do sistema radicular da gramínea (Bernoux et al., 1999; Koutika et al., 1999, 2000).

A densidade do solo de ambas as sucessóes tende a aumentar em profundidade e com a idade da pastagem, principalmente nos primeiros $20 \mathrm{~cm}$ da superfície, sendo mais acentuado na sucessão FB-P20B, com percentuais de aumento na pastagem de 20 e $26 \%$ para as camadas de $0-5$ e $5-10 \mathrm{~cm}$, respectivamente. Esse incremento deve estar relacionado com o pisoteio do gado (Muller et al., 2001, 2004), a exposição do solo a ciclos de umedecimento e secagem (Araújo et al., 2004), a formação de camada selante e o encrostamento do solo em superfície devido ao impacto direto das gotas de chuva e do pisoteio do gado (Lado e Ben-Hur, 2004).

\section{ESTOQUES DE CARBONO NO SOLO}

Os estoques de $\mathrm{C}$ no solo variaram de 4,77 a 22,86 Mg $\mathrm{ha}^{-1}$ até $40 \mathrm{~cm}$ da superfície (Figura 1). Os maiores estoques totais encontram-se em ambiente de pastagem mais antiga (P10A e P20B), devido ao acúmulo de matéria orgânica à superfície e em profundidade. $\mathrm{O}$ ecossistema de pastagem P3A teve decréscimo nos estoques totais de $\mathrm{C}$ equivalente a 6,5 $\mathrm{Mg} \mathrm{ha}^{-1}$. Esse resultado deve estar relacionado ao menor aporte de $\mathrm{C}$ proveniente das pastagens nos primeiros anos de implantação, além do aumento das perdas de C por intermédio das queimadas (Longo e Espíndola, 2000).

Em Latossolos da Amazônia Central, Desjardins et al. (2004) encontraram estoques de $\mathrm{C}$ superiores aos do presente estudo, em camadas de 0-5, 5-10 e 10-20 cm, o conteúdo de C foi de 4,9, 2,7 e 1,9 $\mathrm{kg} \mathrm{m}^{-2}$, respectivamente, em pastagem de Brachiaria humidicola. A tendência de incremento da densidade do solo e do conteúdo de $\mathrm{C}$ também ocorreu no estudo de Bernoux et al. (1999) em área de Latossolo Vermelho Amarelo distrófico com pastagem de 4 anos no Pará.

Em razão da drenagem mais restrita nos ambientes de Rio Branco, esperava-se encontrar maior conteúdo de C. No entanto sabe-se que em ambientes de floresta nativa de ecossistemas Amazônicos a maior parte do C encontra-se armazenada na biomassa da vegetação. Além disso, Melo (2003) sugere que os menores estoques de C no Acre em relação ao restante da Amazônia esteja associado aos ciclos de umedecimento e secagem do solo, e que favoreceriam a mineralização do $\mathrm{C}$ e $\mathrm{N}$. Outro fator que poderia estar 

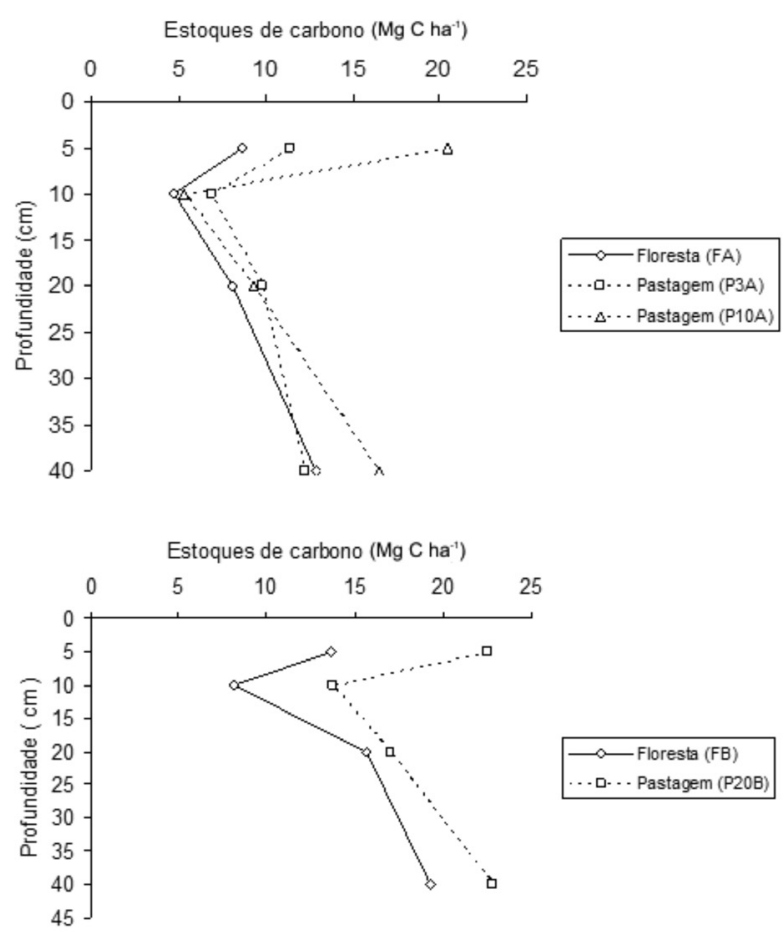

Figura 1 - Estoques de carbono do solo em duas sequências FlorestaPastagem na Amazônia Ocidental, leste do Acre.

associado é a baixa precipitação efetiva (parte da precipitação que fica armazenada no solo até a profundidade das raízes e que fica disponível para os cultivos), devido ao caráter de semi-impedimento de algumas argilas do Acre e aos processos erosivos (Tricart, 1985).

\section{SUBSTÂNCIAS HÚMICAS}

$\mathrm{O} \mathrm{C}$ contido nas substâncias húmicas variou de 0,36 a $20,38 \mathrm{~g} \mathrm{~kg}^{-1}$ (Tabela 2). Nas coberturas vegetais estudadas as maiores proporçóes de $\mathrm{C}$ e $\mathrm{N}$ concentram-se na camada de $0-5 \mathrm{~cm}$ da superfície. De maneira geral, a maior parte do $\mathrm{C}$ das fraçóes húmicas se encontra alocada na fração humina, considerada a mais recalcitrante e com maior interação com a matriz mineral coloidal do solo (Stevenson, 1994). Entretanto, na pastagem de 3 anos, essa proporção se altera nas camadas de 5-10 e 10-20 cm onde as fraçóes $\mathrm{AF}$ e $\mathrm{AH}$ possuem entre 41 e $52 \%$, respectivamente, do somatório de $\mathrm{C}$ das fraçóes húmicas (FAF, FAH e HUM) e, a relação $\mathrm{HUM} /(\mathrm{FAF}+\mathrm{FAH})$ atinge os menores valores (Tabela 2). Os maiores teores de silte na pastagem de 3 anos onde predomina a classe de Argissolo Vermelho-Amarelo plíntico(Tabela 1), pode ter favorecido, quando esse solo foi submetido a queima há cinco anos, a queima de frações do $\mathrm{C}$ consideradas mais lábil, como é o caso da FAF. A relação $\mathrm{C} / \mathrm{N}$ menor para as FAF e FAH demonstra a maior facilidade de oxidação dessas estruturas.
A relação $\mathrm{C} / \mathrm{N}$ mais elevada em área de floresta do que nas áreas de pastagem é atribuído ao incremento no conteúdo de folhas, ramos e galhos, que são de difícil decomposição (Moreira e Costa, 2004). Os valores da relação $\mathrm{C} / \mathrm{N}$ foram mais elevados para o ambiente de mata $\mathrm{FB}$, que pode ser decorrente da maior associaçáo de minerais de argila com a MOS (Duxbury et al., 1989; Zech et al., 1997). Além disso, é válido destacar que a pastagem é um sistema aberto e como tal é natural que se encontre maior relação $\mathrm{C} / \mathrm{N}$ em solo sob floresta. Além disso, folha é a estrutura mais facilmente decomponível e predominante na serapilheira. Quanto a pastagem há elevada produção de raízes que é a principal fonte de $\mathrm{C}$ no solo e é um material mais recalcitrante que a folha.

Com relação a fração leve da matéria orgânica (MOL), ou seja, a porção em que se encontram grande parte dos resíduos de plantas em estágios variados de decomposição (Stevenson, 1994), constata-se impactos negativos quando se compara a floresta nativa e o ecossistema de pastagem correlato para a primeira sequência. Neste caso, a camada superficial $(0-5 \mathrm{~cm}) \mathrm{da}$ pastagem de 3 anos teve reduzida em mais da metade o conteúdo de C contida na MOL. Este fato deve estar associado a reduzida cobertura do solo e a granulometria (maiores proporçóes de silte em relação a argila em superfície, vide Tabela 1) deste ambiente e que influenciaram na taxa decomposição desta fração (Koutika et al., 1999, 2000). A pastagem de 10 anos foi impactada positivamente, principalmente nos 10 primeiros centímetros. Vale salientar que o conteúdo mais acentuado da fração MOL na camada de $5-10 \mathrm{~cm}$ da superfície nas pastagens de 3 e 10 anos (246 e $221 \mathrm{~g} \mathrm{~kg}^{-1}$ de C, respectivamente) devem estar relacionados ao aporte de resíduos do sistema radicular da braquiária.

Para a sequência 2 a MOL após 20 anos da conversão do ecossistema em pastagem de $B$. brizantha decresceu de forma expressiva em quase todas as profundidades. Isso denota que a MOL poderia ser utilizada como indicadora de mudança na qualidade do solo em face de indicar as mudanças no carbono lábil que são afetadas pelas mudanças de uso e fatores ambientais que afetam a atividade de microorganismos (Stevenson, 1994).

A relação $\mathrm{HUM} /(\mathrm{AF}+\mathrm{AH})$ tem sido proposta como indicadora da estabilidade estrutural da MOS, ou seja, quanto mais elevado o valor melhor estabilidade (Labrador Moreno, 1996; Cunha et al., 2005). Os solos de mata possuem valores mais elevados da relação $\mathrm{HUM} /(\mathrm{FAF}+\mathrm{FAH})$ que os ecossistemas de pastagem, com valores mais destacados a partir dos $5 \mathrm{~cm}$ da superfície (Tabela 2). Esse resultado indica que a matéria orgânica proveniente de ecossistemas de mata nativa, em razão de náo ser manejada, as etapas do processo de humificação realizam-se plenamente, o que resulta na maior proporção de fraçóes mais estáveis e de maior estabilidade estrutural. 
Tabela 2 - Substâncias húmicas (FAF, FAH e HUM) e matéria orgânica leve (Mol) em solos de duas sucessões floresta-pastagem da Amazônia Ocidental, Acre

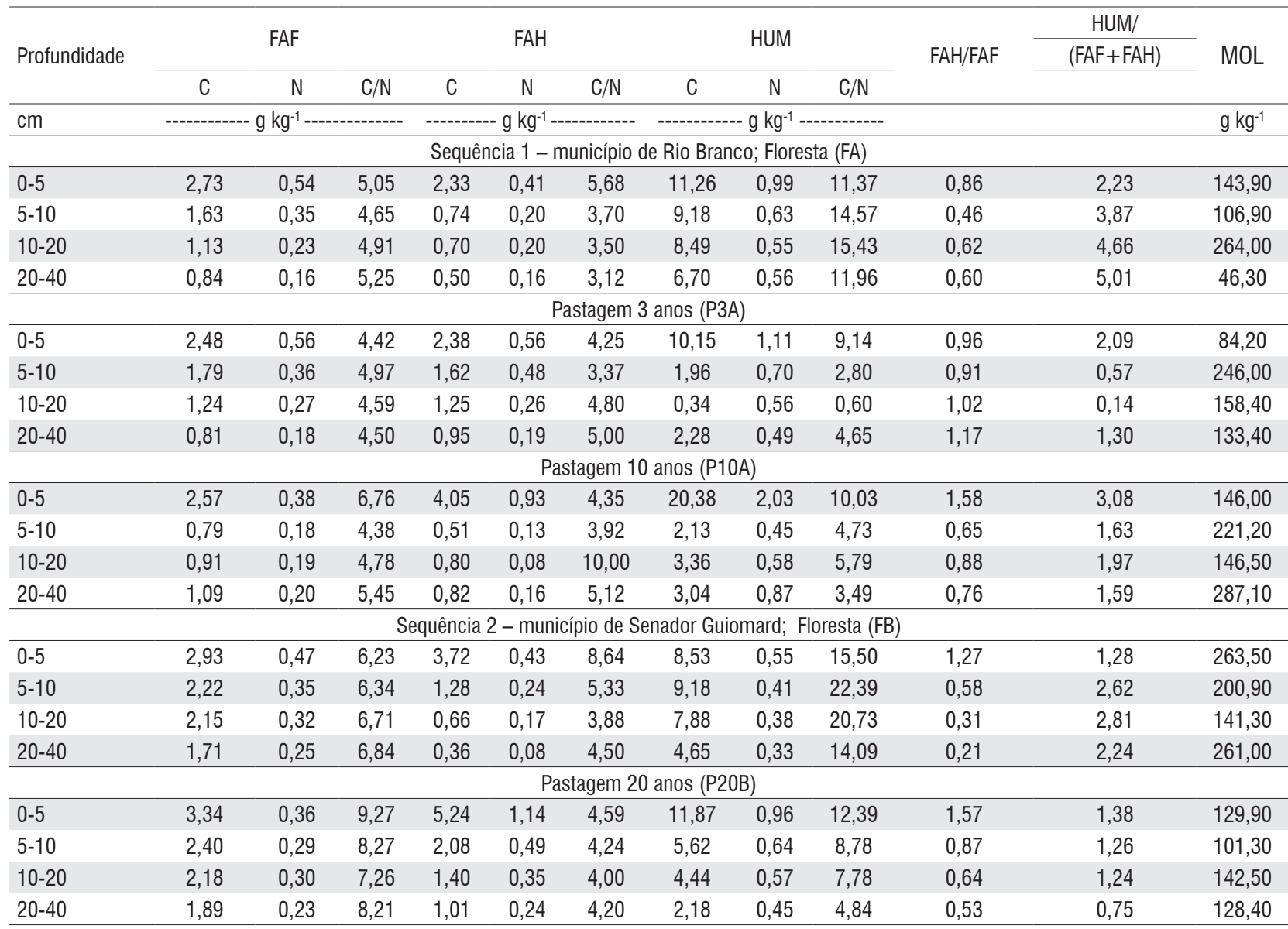

Notação: FAF - Fração ácido fúlvico; FAH - Fração ácido húmico; HUM - Humina; MOL - Matéria orgânica leve.

\section{DESTRIBUIÇÃO DO CARBONO DERIVADO DE SOLOS SOB FLORESTA E PASTAGEM}

Os valores de $\delta^{13} \mathrm{C}$ foram utilizados para calcular a contribuição relativa do $\mathrm{C}$ derivado da floresta $(\mathrm{C} f)$ e da pastagem $(\mathrm{C} p)$. A porcentagem de $\mathrm{C}$ derivado de pastagem $(\mathrm{C} p)$ até $1 \mathrm{~m}$ de profundidade variou de 0,0 a aproximadamente $70 \%$, com as maiores proporçôes mais freqüentes até $20 \mathrm{~cm}$ da superfície. O Cp foi mais expressivo no solo de ecossistema de pastagem de 20 anos (P20B) (Figura 2). O C oriundo da pastagem decresce com a profundidade.

Para a pastagem de 3 anos (P3A) essa contribuiçáo foi pequena e só se refletiu nas profundidades de 10-20 e 40$60 \mathrm{~cm}$. Esse sistema deve conter predominantemente C disponibilizado na queima da biomassa florestal remanescente (Barbosa e Fearnside, 2003). As contribuiçóes de cerca de 12\% e 7\% de C proveniente da pastagem (P3A) nas camadas de 10-20 e 40-60 cm, respectivamente, podem estar relacionadas com a contribuiçáo de raízes de $B$. brizantha. Valores de 4 a $38 \%$ foram constatados para a pastagem de 10 anos (P10A) até $1 \mathrm{~m}$ da superfície. Os resultados demonstram que com o tempo o $\mathrm{C}$ proveniente da pastagem tende a superar o $\mathrm{C}$ oriundo da mata, principalmente em superfície.

Essa tendência de incremento de $\mathrm{C}$ derivado da pastagem com o tempo de utilização também tem sido constatada em outros estudos dessa natureza no Acre (Melo, 2003; Salimon et al., 2007), Amazonas e Pará (Desjardins et al., 2004) e Pará (Bernoux et al., 1999).

\section{VALORES DE $\delta^{13} \mathrm{C}$ NA MOS E NAS FRAÇOES HÚMICAS}

Nos ambientes de floresta, os dois solos tiveram valores de $\delta^{13} \mathrm{C}$ da MOS similares e variaram de - 25,97 \% a $21,31 \%$, com enriquecimento em ${ }^{13} \mathrm{C}$ com a profundidade (Figura 3). Esse enriquecimento em ${ }^{13} \mathrm{C}$ é decorrente da mudança na composição isotópica da matéria orgânica durante sua decomposiçáo ao longo do perfil (Martinelli et al., 1996). Os resultados demonstram o efeito da mudança da cobertura florestal (plantas do tipo C3) para pastagem de $B$. brizantha (planta C4). Porém, na pastagem de 3 anos (P3A), 

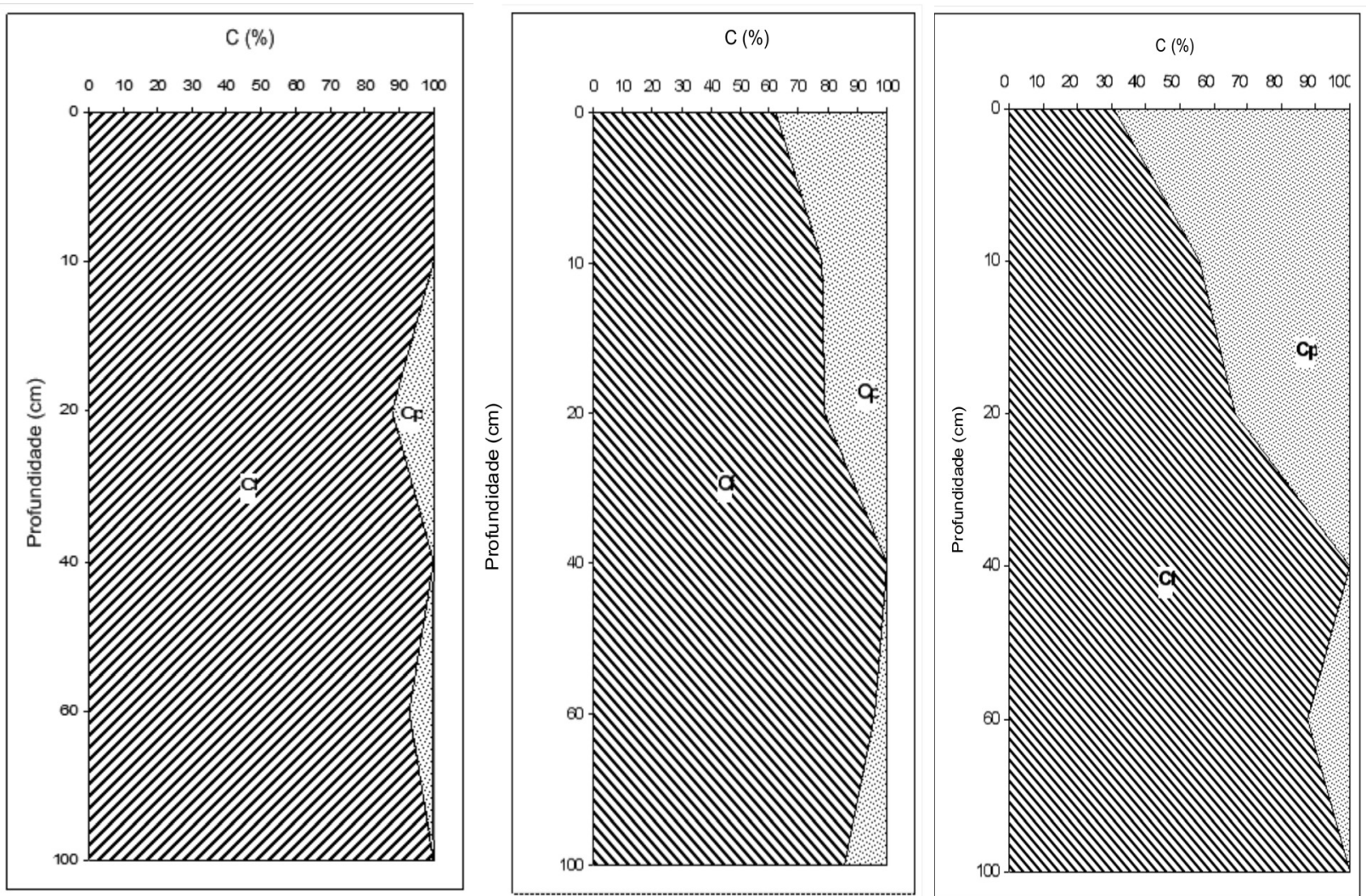

Figura 2 - Distribuição percentual do carbono originário da floresta (Cf) e do carbono originário da pastagem (Cp) até $100 \mathrm{~cm}(1 \mathrm{~m})$ de profundidade em pastagens de $B$. brizantha de 3, 10 e 20 anos no Estado do Acre, Amazônia Ocidental.

o enriquecimento em $\delta^{13} \mathrm{C}$ não foi detectado, sugerindo a predominância de $\mathrm{C}$ remanescente da floresta nativa.

Para os ecossistemas de pastagem P10A e P20B o enriquecimento em $\delta^{13} \mathrm{C}$ pode ser percebido, sendo mais acentuado na pastagem de 20 anos. Esses resultados indicam que a diferença deve estar relacionada ao maior tempo de utilização e a menor infestação de plantas invasoras.

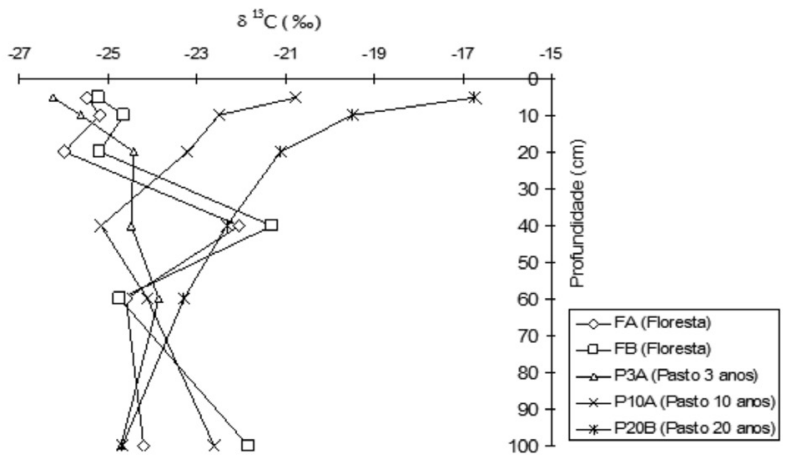

Figura 3 - Variação de $\delta^{13} C$ da matéria orgânica do solo até $1 \mathrm{~m}$ de profundidade em duas sequências floresta-pastagem da Amazônia Ocidental, Acre.
$\mathrm{Na}$ pastagem mais antiga (P20B) há também maior proporção de $\mathrm{C}$ derivado da gramínea em profundidade, o que pode contribuir substancialmente para o seqüestro de $\mathrm{CO}_{2}$ em formas mais estáveis da MOS em longo prazo. Houve incremento em $\delta^{13} \mathrm{C}$ no ambiente de mata das duas sucessóes (FA e FB), sendo mais acentuado em profundidade para a FB. A hipótese mais provável é que esse carbono poderia ser remanescente de matéria orgânica antiga e estável, proveniente de uma vegetação anterior mais rica em ${ }^{13} \mathrm{C}$ que a atual (Martinelli et al., 1996; Lucas et al., 1993). Em razão do clima seco pretérito (Kronberg e Benchimol, 1992, 1993), provavelmente a regiáo possa ter sido coberta por uma espécie de savana em que predominavam gramíneas de ciclo C4 (Desjardins et al., 1996; Lucas et al., 1993). Estudos realizados na regiáo não corroboram com este resultado (Melo, 2003). Contudo, alguns estudos na Amazônia brasileira utilizando a abundância natural do ${ }^{13} \mathrm{C}$ têm constatado enriquecimento de $\delta^{13} \mathrm{C}$ com a profundidade em áreas atualmente ocupadas por florestas, denotando que esses locais passaram por mudanças climáticas pretéritas e, por conseguinte, na tipologia florestal 
dominante (Lucas et al., 1993; Desjardins et al., 1996; Pessenda et al., 1998).

A matéria orgânica leve (MOL), por conter restos de vegetais ainda em decomposiçáo reflete a cobertura vegetal existente em ambiente de mata e de pastagem (Tabela 3 ). $\mathrm{O}$ maior enriquecimento em $\delta{ }^{13} \mathrm{C}$ foi constatado para o $\mathrm{C}$ da MOL, e os menores para o $\mathrm{C}$ da fração HUM. Esse enriquecimento foi mais evidente nas pastagens mais antigas, com pouco material da braquiária na pastagem mais nova (P3A). O maior enriquecimento do $\mathrm{C}$ da $\mathrm{MOL}$ ocorre em decorrência do grande aporte de C via sistema radicular ramificado e com rápida ciclagem da braquiária (Fernandes et al., 1999). A baixa proporção de C derivado da gramínea na MOL da pastagem mais jovem (P03A), provavelmente, se deve ao grande aporte de material vegetal particulado em vários estádios de carbonização após a queima dos resíduos da floresta, além da incorporação de raízes mortas das plantas da floresta até camadas mais profundas (Makewitz et al., 2004; Luizão, 2007).

Tabela 3 - Variação do $\delta^{13} \mathrm{C}$ na MOL e frações húmicas com a profundidade em ecossistemas de mata e pastagem do Acre

\begin{tabular}{|c|c|c|c|c|c|}
\hline \multirow[b]{2}{*}{ Profundidade } & \multicolumn{3}{|c|}{ Sequência 1} & \multicolumn{2}{|c|}{ Sequência 2} \\
\hline & Floresta (FA) & $\begin{array}{l}\text { Pastagem } \\
\text { (P03A) }\end{array}$ & $\begin{array}{c}\text { Pastagem } \\
\text { (P10A) }\end{array}$ & Floresta (FB) & Pastagem (P20B) \\
\hline $\mathrm{cm}$ & \multicolumn{5}{|c|}{ - } \\
\hline \multicolumn{6}{|c|}{ Matéria Orgânica Leve (MOL) } \\
\hline $0-5$ & $-28,48$ & $-26,25$ & $-18,22$ & $-27,34$ & $-13,61$ \\
\hline $5-10$ & $-27,8$ & $-25,74$ & $-17,24$ & $-26,84$ & $-14,85$ \\
\hline $10-20$ & $-28,24$ & $-25,17$ & $-18,15$ & $-27,42$ & $-14,08$ \\
\hline $20-40$ & $-27,69$ & $-25,74$ & $-17,14$ & $-27,29$ & $-18,17$ \\
\hline Valor médio & $-28,05$ & $-25,73$ & $-17,69$ & $-27,22$ & $-15,18$ \\
\hline \multicolumn{6}{|c|}{ Fração Ácido Fúlvico (FAF) } \\
\hline $0-5$ & $-23,58$ & $-24,84$ & $-17,92$ & $-25,28$ & $-18,85$ \\
\hline $5-10$ & $-20,55$ & $-25,28$ & $-25,69$ & $-24,13$ & $-18,88$ \\
\hline $10-20$ & $-24,09$ & $-25,68$ & $-20,51$ & $-23,16$ & $-21,55$ \\
\hline $20-40$ & $-23,95$ & $-29,21$ & $-25,17$ & $-25,31$ & $-22,75$ \\
\hline $40-60$ & $-19,51$ & $-28,82$ & $-25,27$ & $-24,96$ & $-22,59$ \\
\hline $60-100$ & $-20,69$ & $-28,45$ & $-22,54$ & $-21,01$ & $-24,00$ \\
\hline Valor médio & $-22,06$ & $-27,05$ & $-22,85$ & $-23,98$ & $-21,44$ \\
\hline \multicolumn{6}{|c|}{ Fração Ácido Húmico (FAH) } \\
\hline $0-5$ & $-18,49$ & $-11,75$ & $-15,73$ & $-18,06$ & $-16,05$ \\
\hline $5-10$ & $-17,59$ & $-11,15$ & $-10,26$ & $-16,6$ & $-15,84$ \\
\hline $10-20$ & $-15,65$ & $-11,19$ & $-13,89$ & $-16,19$ & $-15,37$ \\
\hline $20-40$ & $-16,05$ & $-8,83$ & $-13,86$ & $-17,87$ & $-13,52$ \\
\hline $40-60$ & $-15,12$ & $-15,01$ & $-14,62$ & $-17,57$ & $-17,71$ \\
\hline $60-100$ & $-16,21$ & $-15,20$ & $-15,54$ & $-19,15$ & $-16,96$ \\
\hline \multicolumn{6}{|c|}{ Fração Humina (HUM) } \\
\hline $0-5$ & $-26,54$ & $-26,04$ & $-20,64$ & $-23,68$ & $-17,00$ \\
\hline $5-10$ & $-22,61$ & $-24,45$ & $-21,01$ & $-26,48$ & $-17,61$ \\
\hline $10-20$ & $-24,13$ & $-23,75$ & $-22,93$ & $-23,81$ & $-20,76$ \\
\hline $20-40$ & $-20,59$ & $-17,09$ & $-23,24$ & $-23,37$ & $-21,80$ \\
\hline $40-60$ & $-24,15$ & $-20,73$ & $-20,11$ & $-23,81$ & $-21,04$ \\
\hline $60-100$ & $-18,17$ & $-19,60$ & $-18,71$ & $-25,03$ & $-25,74$ \\
\hline Valor médio & $-22,70$ & $-21,94$ & $-21,11$ & $-24,36$ & $-20,66$ \\
\hline
\end{tabular}


Para as substâncias húmicas $(\mathrm{SH})$ até $1 \mathrm{~m}$ de profundidade os valores de $\delta^{13} \mathrm{C}$ variaram de - 8,83\%o a - 29,21\%o, indicando que as $\mathrm{SH}$ originaram-se tanto de plantas do tipo C3 como C4. Dentre as fraçóes húmicas ocorreu maior enriquecimento em $\mathrm{C}$ derivado da pastagem nos $\mathrm{AH}$, seguido pelos AF e HUM (Tabela 3).

A menor proporção de $\mathrm{C}$ derivado da pastagem na fração HUM era esperada, devido a forte interação dessa fração com a fração coloidal mineral do solo (Canellas et al., 2000; Corrêa et al., 2003), resultando em menor taxa de ciclagem e, conseqüentemente, menor substituição do $\mathrm{C}$ antigo da floresta pelo derivado da pastagem. A maior proporção de $\mathrm{C}$ derivado da gramínea na FAH (valores médios variaram de $-12,19$ a 17,57 \%o) em relação a FAF (em média -21,40 a $-27,05 \%$ ) indica que as rotas de humificação tradicionais (Stevenson, 1994), não são contempladas plenamente. Nelas, os produtos da quebra de resíduos vegetais (principalmente polifenóis) são transformados inicialmente em $\mathrm{AF}$, que por vezes são polimerizados/condensados para originar os $\mathrm{AH}$ e então, a fração HUM. Isso sugere que a FAH pode estar sendo formada independentemente da passagem dos compostos orgânicos pela FAF, numa rota alternativa de humificação de herança dos resíduos vegetais. Segundo Stevenson (1994), existem vias de formação das substâncias húmicas no solo com possibilidade de formação a partir da alteração direta de compostos lignificados, por meio de demetilação e oxidação, com incorporação de grupamentos carboxílicos e grupamentos amino. Esta forma seria bem mais rápida, sem a alteração e decomposição mais acentuada de compostos originais e síntese de novos compostos humificados. Este processo é referido como "Via de Herança", destacando-se como característico na formação da fração humina em ambientes menos propícios à atividade microbiana, como em solos saturados por água.

\section{CONCLUSÕES}

Nas duas sequências estudadas, a transformação de áreas sob mata nativa em pastagens de $B$. brizantha ocorreu incremento nos estoques de carbono nas camadas superficiais. Esse comportamento, mais destacado na sequência 2 (Latossolo Vermelho Amarelo está associado a maior estabilidade deste ambiente (relevo plano), a distrofia, baixo conteúdo de $\mathrm{P}$ e a contribuição das raízes da gramínea forrageira.

Constataram-se incremento nos valores de $\delta^{13} \mathrm{C}$ do solo com o tempo de utilização da pastagem, em ambas as sucessóes, sendo mais expressivo para pastagem de 20 anos. Os valores de $\delta^{13} \mathrm{C}$ para as substâncias húmicas indicaram que a fração ácido húmico $(\mathrm{FAH})$ apresentou maior participação de C derivado de plantas C4.

A estabilidade estrutural da MOS, inferida pela relação humina com as fraçôes ácido fúlvico e ácido húmico (HUM/
$\mathrm{FAF}+\mathrm{FAH})$, tende a decrescer nos ecossistemas de pastagem quando comparada com a mata nativa.

\section{AGRADECIMENTOS}

Os autores agradecem ao Programa Internacional de Bolsas de Pós-Graduação da Fundação Ford (International Fellowships Programa - IFP) pela bolsa de Pós-Graduação concedida ao primeiro autor deste artigo e ao suporte financeiro para a viagem de campo. A Embrapa - Acre pelo apoio na realização de parte das análises físicas e químicas de solo, na pessoa do pesquisador, desta instituiçáo, Paulo Guilherme Salvador Wadt. Ao Governo do Estado do Acre, representado pela Secretaria de Agricultura e Pecuária do Acre e ao Departamento de Solos e Nutriçáo de Plantas da Universidade Federal de Viçosa, por proporcionarem condiçóes para a realização desta pesquisa. Aos proprietários das Fazendas Batista e Ouro Verde por permitirem realizar o presente estudo em suas propriedades.

\section{BIBLIOGRAFIA CITADA}

Acre. Governo do Estado do Acre. 2006. Programa Estadual de Zoneamento Ecológico-Econômico do Estado do Acre. Zoneamento Ecológico-Econômico do Acre Fase II: documento Sintese - Escala 1:250.000. SEMA, Rio Branco, Acre. 356 pp.

Anderson, J. M.; Ingram, J. S. I. 1993. Tropical soil biology and fertility: a handbook of methods. CAB International, Wallingford. $221 \mathrm{pp}$.

Araujo, E. A., Lani, J. L., Amaral, E. F.; Guera, A. 2004. Land use and physical and chemical properties of distrophic Argissoil in Western Amazonia. Revista Brasileira de Ciência do Solo, 28: 307-315. (In Portuguese).

Barbosa, R.I.; Fearnside, P.M. 2003. Burning of pasture in Amazonia:short-term changes in soil carbon stocks. Brazilian Journal of Ecology, 1-2: 11-16.

Bernardes, M.C.; Martinelli, L.A.; Krusche, A.V.; Gudeman, J.; Moreira, M.M.; Victoria, R.L.; Ometto, J.P.H.B; Ballester, M.V.R.; Audenkampe, A.K.; Richey, J.E.; Hedges, J.I. 2004. Riverine organic matter composition as a function of land use changes, Southwest Amazon. Ecological Applications, 14:S263-S279.

Bernoux, M.; Cerri, C.C.; Neil, C.; Moraes, J.F.L. 1998a. The use of stable isotopes for estimating soil organic matter turnover rates. Geoderma, 82: 43-58.

Bernoux, M. Cerri, C.; Arrrouays, D.; Volkoff, B .; Jolivet, C. 1998b. Bulk densities of Brazilian Amazon soils related to other soil properties. Soil Science Society of America Journal, 62: 743-749.

Bernoux, M.; Feigl, B.J.; Cerri, C.C.; Geraldes, A.P.A.; Fernandes, S.A.P. 1999. Soil carbon and nitrogen of a pasture-forest cronossequence in Paragominas, Pará, Brazil. Scientia Agrícola, 56: 1-11. (In Portuguese).

Brasil. 1976. Ministério das Minas e Energia. Departamento Nacional de Produção Mineral. Projeto Radambrasil. Folha SC. 
19 Rio Branco; geologia, geomorfologia, pedologia, vegetação, uso potencial da terra. IBGE, Rio de Janeiro, 458 pp. (v. 12).

Bremner, J.M.; MULVANEY, C.S. 1982. Total nitrogen. P.595-624. In: PAGE, A.L. Methods of soil analysis. American Society of Agronomy, Madison.

Canellas, L.P.; Berner, P.G.; Silva, S. G.; Barros, M.B.S.; Santos, G. A. 2000. Fractions of the organic matter in six soils of a topossequence in the Rio de Janeiro State, Brazil. Pesquisa Agropecuária Brasileira, 35: 133-143. (In Portuguese).

Corrêa, M. M.; Ker, J. C.; Mendonça, E. S.; Ruiz, H. A.; Bastos, R. S. 2003. Soil physical, chemical and mineral attributes of Várzeas de Sousa, Paraíba, Brazil. Revista Brasileira de Ciência do Solo, 27: 311-324.

Cunha, T.J.F.; Canellas, L.P.; Santos, G.A.; Canellas, L. P. R.; Pasqualoto, L. 2005. Fracionamento da matéria orgânica humificada de solos brasileiros, p.54-80. In: Canellas, L. P.; Santos, G. A. Humosfera: tratado preliminar sobre a quimica das substâncias húmicas. Universidade Estadual do Norte Fluminense, Campos dos Goytacazes, Rio de Janeiro.

Desjardins, T.; Andreux, F.; Volkoff, B.; Cerri, C. C. 1994. Organic carbon and ${ }^{13} \mathrm{C}$ contents in soils and soil size- fractions, and their changes due to deforestation and pasture installation in eastern Amazonia. Geoderma, 61: 103-118.

Desjardins, T.; Carneiro Filho, A.; Mariotti, A.; Chauvel, A.; Girardin, A. 1996. Changes of the forest-savanna boundary in Brazilian Amazônia during the Holocene revealed by stable isotope ratios of soil organic carbon. Oecologia, 108: 749-756.

Desjardins, T.; Barros, E.; Sarrazin, M.; Girardin, C.; Mariotti, A. 2004. Effects of forest conversion to pasture on soil carbon content and dynamics in Brazilian Amazonian. Agriculture Ecosystems \& Environment, 103: 365-373.

Dias-Filho, M.B.; Andrade, C.M.S. 2006. Pastagens no trópico úmido. Belém, PA: Embrapa Amazônia Oriental. 30p. (Embrapa Amazônia Oriental. Documentos, 241).

Duxbury, J.M.; Smith, M.S.; Doran, J.M. S. 1989. Soil organic matter as a source and a sink of plant nutrients, p.33-67. In: Coleman, D.C.; Oades, J.M.; Uehara, G. Dynamics of soil organic matter in tropical ecossystems. University of Hawaii, Honolulu.

Embrapa. Centro Nacional de Pesquisa de Solos. 1997. Manual de métodos de análise de solo. 2.ed. Embrapa Solos, Rio de Janeiro. 212 pp.

Fearnside, P.M.; Barbosa, R.I. 1998. Soil carbon changes from conversion of forest to pasture in Brazilian Amazonia. Forest Ecology and Management, 108: 147-166.

Fearnside, P.M. 2002. Fogo e emissão de gases de efeito estufa dos ecossistemas florestais da Amazônia brasileira. Estudos Avançados, 16: 99-123.

Feigl, B. J.; Melillo, J.; Cerri, C. C. 1995. Changes in the origin and quality of soil organic matter after pasture introduction in Rondônia. Plant and Soil, 175: 21-29.

Fernandes, F.A.; Cerri, C.C.; Fernandes, A.H.B.M. 1999. Alteraçôes na matéria orgânica de um Podzol Hidromórfico pelo uso com pastagens cultivadas no Pantanal Mato-Grossense. Pesquisa Agropecuária Brasileira, 34: 1943-1951.
García-Oliva, F.; Casar, I.; Morales, P.; Maass, J. M. 1994. Forest-topasture conversion influences on soil organic carbon dynamics in a tropical deciduous forest. Oecologia, 99: 392-396.

Gouveia, S. E. M.; Pessenda, L. C. R. 1999. Datação da fração humina da matéria orgânica do solo e sua comparação com idades ${ }^{14} \mathrm{C}$ de carvôes fósseis. Química Nova, 22: 810-814.

Hiradate, S.; Nakadai, T., Shindo, H.; Yoneyama, T. 2004. Carbon source of humic substances in some Japanese volcanic ash soils determined by carbon stable isotopic ratio $\delta^{13} \mathrm{C}$. Geoderma, 119:133-141.

INPE. 2008. Projeto de Estimativa do Desflorestamento Bruto da Amazônia. Desflorestamento nos Municípios da Amazônia Legal Relatório 1998-2007. (http://www.dpi.inpe.br/prodesdigital/ prodesmunicipal). Acesso: 12/02/2009.

Kauffman, J.B.; Cummings, D.L.; Ward, D.E.; Babbit, R. 1995. Fire in the Brazilian Amazon: 1.biomass, nutrient pools, and losses in slashed primary forests. Oecologia, 104: 397-408.

Koutika, L.S.; Choné, Th.; Andreux, F.; Burtin, G. \& Cerri, C.C. 1999. Factors influencing carbon decomposition of topsoils from the Brazilian Amazon Basin. Biology and Fertility of Soils, 28: 436-438.

Koutika, L.S.; Choné, Th.; Andreux, F. \& Cerri, C.C. 2000. Carbon decomposition of the topsoils and soil fractions under forest and pasture in the western Brazilian Amazon basin, Rondônia. Biology and Fertility of Soils, 30: 284-287.

Kronberg, B.I.; Benchimol, R.E. 1992. Geochemistry and geocronoly of surficial Acre Basin sediments (Western Amazonia): key information for climate reconstruction. Acta Amazonica, 22: 51-69.

Kronberg, B.; Benchimol, R. 1993. Aridez no Acre: a história climática de uma região. Ciência Hoje, 16: 44-47.

Labrador Moreno, J. 1996. La matéria organica en los agrosistemas. Ministerio de Agricultura, Pesca y Alimentación, Madri, 176 pp.

Lado, M.; Ben-Hur, M. 2004. Soil mineralogy effects on seal formation, runoff and soil loss. Applied Clay Science, 24: 209224.

Latrubesse, E. M. \& Iriondo, M. A probable scenario for a dry climate in Central Amazonia during the Late Quaternary. Quaternary International, v.21, n., p.121-128, 1994.

Lima, H.N.; Mello, J.W.V.; Schaeffer, C.E.G.R.; Ker, J.C. 2005. Dinâmica da mobilização de elementos em solos da Amazônia submetidos à inundação. Acta Amazonica, 35: 317-330.

Longo, R.M.; Espíndola, C.R. 2000. Alteraçôes em características químicas de solos da região Amazônica pela introdução de pastagens. Acta Amazonica, 30: 71-80.

Lucas, Y.; Soubiés, F.; Chauvel, A.; Desjardins, T. 1993. Estudos do solo revelam alteraçóes climáticas da Amazônia. Ciência Hoje, 16: 36-39.

Luizao, F.J. 2007. Ciclos de nutrientes na Amazônia: respostas às mudanças ambientais e climáticas. Ciência e Cultura, 59: 31-36.

Makewitz, D.; Davidson, E.; Moutinho, P.; Nepstad, D. 2004. Nutrient loss and redistribution after forest clearing on a highly weathered soil in Amazonia. Ecological Applications, 14: S177-S199. 
Martinelli, L.A.; Pessenda, L.C.R.; Espinoza, E.; Camargo, P.B.; Telles, E.C.; Cerri, C.C.; Victoria, R.L.; Aravena, R.; Richey, J.; Trumbore, S. 1996. Carbon-13 variation with depth in soils of Brazil and climate change during the quaternary. Oecologia, 106: 376-381.

Melo, A. W. F. Avaliaçâoo do estoque e composição isotópica do carbono do solo do Acre. 2003. Dissertaçáo (Mestrado em Ecologia de Agroecossistemas) - Escola Superior de Agricultura "Luiz de Queiroz”, Universidade de São Paulo, Piracicaba, SP.74 pp.

Moraes, J. F. L.; Volkoff, B.; Cerri, C. C.; Bernoux, M. 1996. Soil properties under Amazon forest and changes due to pasture installation in Rondônia, Brazil. Geoderma, 70: 63-81.

Moreira, A.; Costa, D.G. 2004. Dinâmica da matéria orgânica na recuperação de clareiras da floresta amazônica. Pesquisa Agropecuária Brasileira, 39:1013-1019.

Muller, M.M.L.; Guimaraes, M.D.; Desjardins, T.; Martins, P.F.D. 2001. Pasture degradation in the Amazon region: soil physical properties and root growth. Pesquisa Agropecuária Brasileira, 36: 1409-1418.

Muller, M.M.L.; Gimarães, M.F.; Desjardins, T.; Mitja, D. 2004. The relationship between pasture degradation and soil properties in the Brazilian Amazon: a case study. Agriculture Ecosystems \& Environment, 103: 279-288.

Oliveira, H.; Bardales, N.G.; Amaral, E.F.; Amaral, E.F.; Lani, J.L.; Araújo, E.A. 2006. Relatório da aptidão natural de uso da terra no estado do Acre. Relatório II Fase SEMA, ZEE/AC. 59 pp.

Pereira, W. L. M.; Veloso; C. A. C.; Gama, J. R. N. F. 2000. Propriedades químicas de um Latossolo Amarelo cultivado com pastagens na Amazônia Oriental. Scientia Agricola, 57: 531-537.

Pessenda, L.C.R.; Gomes, B.M.; Aravena, R.; Ribeiro, A.S.; Boulet, R.; Gouveia, S.E.M. 1998. The carbon isotope record in soils along a forest-cerrado ecosystems transect: implications for vegetation changes in the Rondônia state, Southwestern Brazilian Amazon region. The Holocene, 8: 599-603.

Ponnamperuma, F.N. 1972. The chemistry of submerged soils. Advances in Agronomy, 24: 29-96.

Piccolo, A.; Conte, P.; Spaccini, R.; Mbagwu, J.S.C. 2005. Influence of land use on the characteristics of humic substances in some tropical soils of Nigeria. European Journal of Soil Science, 56: 343-352.
Salimon, C. I.; Wadt, P.G.S. \& Melo, A.W.F. 2007. Dinâmica do carbono na conversão de florestas para pastagens em Argissolos da Formação Geológica Solimôes, no Sudoeste da Amazônia. Revista de Biologia e Ciências da Terra, 7:29-38.

Smith, B. N.; Epstein, S. 1971. Two categories of ${ }^{13} \mathrm{C} /{ }^{12} \mathrm{C}$ ratios for higher plants. Plant Physiology, 47: 380-384.

Spaccini, R.; Mbagwu, J.S.C.; Conte P.; Piccolo, 2006. A. Changes of humic substances characteristics from forested to cultivated soils in Ethiopia. Geoderma, 132: 9-19.

Stevenson, FJ. 1994. Humus chemistry: genesis, composition, reactions. John Wiley, New York. 496 pp.

Stevenson, F.J.; Cole, M. 1999. Cycles of soil: carbon, nitrogen, phosphorus, sulfur, micronutrients. John Wiley, New York. 427 pp.

Swift, R.S. 1996. Organic matter characterization, p.1018-1020. In: Sparks, D.L. (Ed.). Methods of soil analysis. Part 3. Chemical methods. Soil Science Society American Book Series: 5. Madison, WI.

Tedesco, M.J.; Gianello, C.; Bissani, C.A.; Bohnen, H. \& Volkweiss, S.J. 1995. Análise de solo, plantas e outros materiais. 2.ed. Porto Alegre, Universidade Federal do Rio Grande do Sul,. 174 pp.

Tricart, J. 1985. Evidence of Upper Pleistocene dry climates in Northern South America, p. 197-217. In: Douglas, I.; Spencer, T. (Eds.) Environmental change and tropical geomorphology. London; Boston: Allen \& Unwin.

Veldkamp, E. 1994. Organic carbon turnover in three tropical soils under pasture after deforestation. Soil Science Society American Journal, 58: 175-180.

Volkoff, B.; Cerri, C.C. 1981. Húmus em solos da floresta amazônica na região do rio Madeira. Revista Brasileira de Ciência do Solo, 5: 15-21.

Yeomans, A.; Bremner, J.M. 1988. A rapid and precise method for routine determination of organic carbon in soil. Communication in Soil Science and Plant Analysis. 19:1467-1476.

Zech, W.; Senesi, N.; Guggenberger, G.; Kaiser, K.; Lehmann, J.; Miano, T.M.; Miltner, A.; Schroth, G. 1997. Factors controlling humification and mineralization of soil organic matter in the tropics. Geoderma, 79: 117-161.

Recebido em 24/02/2010

Aceito em 19/05/2010 